\title{
Identificação de necessidades de informação para a construção de um banco de dados corporativo em uma distribuidora de energia elétrica: um estudo de caso
}

Identification of information needs for the construction of a corporate database on a distributor of electricity: a case study.

\author{
Anna Carollyna de Bulhões Moreira ${ }^{1}$ \\ Emilson Ferreira Garcia Junior ${ }^{2}$ \\ Luzia Góes Camboim ${ }^{3}$
}

Artigo submetido em nov./2014 e aceito para publicação em mar./2015.

\begin{abstract}
RESUMO
O presente trabalho teve por objetivo investigar como se deu o processo de identificação de necessidades de informação dos usuários internos numa empresa distribuidora de energia elétrica, relativas à atividade de Gestão de Perdas não-Técnicas. Essas perdas caracterizam-se por resultarem, principalmente, de ligações clandestinas e fraudes nos equipamentos medidores e têm sido foco de grande atenção por parte da Agência Nacional de Energia Elétrica - ANEEL e das empresas distribuidoras brasileiras, pelo vulto de recursos desviados que representa. O processo de desenvolvimento da solução sistêmica idealizada para essa empresa, baseada numa arquitetura de Data Warehouse, para apoio no processo de tomada de decisão relativa à gestão dessas perdas, teve início com o levantamento dos requisitos de informação, ou seja, a identificação das necessidades de informação dos tomadores de decisão nesse processo.
\end{abstract}

Palavras-chave: Necessidades de informação; Data Warehouse; Perdas não-técnicas.

\begin{abstract}
The present study aimed to investigate how was the process of identifying information needs of internal users in a company that distributes electricity, relating to activity management Losses nonTechniques. These losses are characterized by result mainly from illegal connections and fraud in the meters and equipment have been the focus of great attention by the National Electric Energy Agency ANEEL and the Brazilian distribution companies, the shape of which is diverted resources. The process of developing systemic idealized solution for the enterprise based on a Data Warehouse architecture, to support the decision-making on the management of these losses process began with a survey of information requirements, ie, the identification of needs information of decision makers in this process.
\end{abstract}

Keywords: Information needs; Data Warehouse; Non-technical losses.

\section{INTRODUÇÃO}

\footnotetext{
1 Mestranda no Programa de Pós-Graduação em ciência da informação, da Universidade Federal da Paraíba (UFPB). carollynabulhoes@gmail.com

${ }^{2}$ Mestrando no Programa de Pós-Graduação em ciência da informação, da Universidade Federal da Paraíba (UFPB). emilson.uepb@gmail.com

${ }^{3}$ Doutoranda no Programa de Pós-Graduação em ciência da informação, da Universidade Federal da Paraíba (UFPB). Icamboim@terra.com.br
} 
Revista Tecnologia e Sociedade, Curitiba, v. 11, n. 23, 2015

ISSN (versão online): 1984-3526

ISSN (versão impressa): 1809-0044

Os estudos de usuários têm sido objeto de investigação por mais de 40 anos no âmbito da Ciência da Informação (BAPTISTA, 2007), sendo que os mesmos vêm passando de uma abordagem centrada no sistema para uma abordagem centrada no usuário, conforme atesta a evolução dos paradigmas da Ciência da Informação, abordados por Capurro (2003), que migram do paradigma tradicional para uma perspectiva cognitiva/social.

Nessa nova perspectiva, argumenta Ferreira (1995), considera-se que a informação só tem sentido quando integrada a algum contexto, constituindo-se de um dado incompleto, ao qual o indivíduo atribui um sentido a partir da intervenção de seus esquemas anteriores. Assim, para a autora, o ponto crítico deixa de ser quem usa sistemas de informação e com que frequência e passa a ser com que propósitos os sistemas são utilizados e como eles efetivamente ajudam, ou seja, busca-se a resposta à questão "informação para quê?".

Nesse sentido, Ferreira (1995, p.5) afirma que "a informação não mais se configura como tijolos colocados uns sobre os outros, mas sim como a argila, à qual o próprio indivíduo dará o formato, a consistência e o sentido que the convier".

Com o intuito de contribuir, através da exposição de um caso prático, para o alargamento desse entendimento, esse trabalho vem expor o esquema usado para identificação das necessidades de usuários internos de uma distribuidora de energia elétrica, atuante em nível nacional, quando da construção de uma solução sistêmica para combate a um tipo específico de perdas em seu processo.

Para levantamento dos dados dessa pesquisa, foi feita uma entrevista com um roteiro semi-estruturado junto à profissional responsável pelo mapeamento das atividades envolvidas no trabalho com essas perdas à época da implantação da solução sistêmica. Os dados coletados foram analisados à luz da teoria sobre modelos de usuários.

\section{COMPORTAMENTO INFORMACIONAL: AS NECESSIDADES DOS USUÁRIOS E O SEU CAMPO TEÓRICO}

O entendimento das necessidades de usuários passa inicialmente pelo entendimento do que seja um usuário de informação. De acordo com Sanz Casado (1994, p. 19), o usuário de informação ou grupo de usuários é: "[...] aquele indivíduo 
Revista Tecnologia e Sociedade, Curitiba, v. 11, n. 23, 2015

ISSN (versão online): 1984-3526

ISSN (versão impressa): 1809-0044

que necessita de informação para o desenvolvimento de suas atividades". Tal definição, porém, desconsidera as diversas possibilidades de ação do sujeito na apreensão daquilo de que realmente necessita.

No conceito de Figueiredo, Morais e Ramalho (2013, p. 100), por sua vez, observa-se uma inter-relação entre busca e satisfação, ao afirmarem que o usuário é um "[...] indivíduo que necessita de informação - não importando a profissão que exerça, nem grupo ao qual pertença - acessa-a e a usa para desenvolver suas atividades.".

Assim, "o usuário da informação é visto, como [...] o elemento fundamental de todos os sistemas de informação [...] o agente essencial na concepção, avaliação, enriquecimento adaptação estímulo e funcionamento de qualquer sistema de informação" (GUINCHAT; MENOU, 1994, p.482).

Essas definições explicitam a necessidade de informação como elemento caracterizador de quem poderia ser considerado e, portanto, estudado como usuário de informação.

Miranda (2006) apresenta um percurso histórico da construção (e mudança) das abordagens de necessidades de informação tradicionais para as alternativas. Dentro dessas duas perspectivas, a necessidade de informação é o estado de necessidade de algo que o pesquisador chama de informação, focada no que o sistema possui, e não no que o usuário precisa (visão tradicional) ou a necessidade de informação surge quando o usuário reconhece que existe algo errado em seu estado de conhecimento e deseja resolver essa anomalia (visão alternativa). A autora ainda afirma que nem toda necessidade se transforma em uma atividade de busca de informação, devendo haver mecanismos de ativação para que ela se efetive. (MIRANDA, 2006, p.103)

Miranda (2006) define, então, necessidade de informação como um estado ou um processo no qual alguém percebe a insuficiência ou inadequação dos conhecimentos necessários para atingir objetivos e/ou solucionar problemas, sendo essa percepção composta de dimensões cognitivas, afetivas e situacionais. Logo, para ela, a necessidade surge da falta de sentido percebida nas situações enfrentadas, causando uma lacuna de sentido que se busca preencher com o uso de informações. 
Revista Tecnologia e Sociedade, Curitiba, v. 11, n. 23, 2015

ISSN (versão online): 1984-3526

ISSN (versão impressa): 1809-0044

González de Gomez (1990) destaca ainda, que uma necessidade de informação se apresenta a partir de outras necessidades originadas em diversos contextos, da experiência e da ação. Tais estudos relacionados às necessidades informacionais oferecem subsídios para um aprofundamento da compreensão do comportamento e todo o processo de busca e uso da informação.

É interessante ressaltar que Figueiredo (1999, p.19), com o intuito de facilitar o entendimento de quais sejam as necessidades dos usuários e, portanto, melhor atendê-las, dividiu os usuários em três diferentes tipos, cada um com diferentes necessidades de informação: o grupo dos pesquisadores das áreas básicas tradicionais (que não buscam informações específicas mas, aprofundamento do conhecimento); o grupo dos pesquisadores das ciências aplicadas, pessoal de desenvolvimento de produtos, profissionais de marketing e engenheiros (buscam respostas a questões específicas) e o grupo dos executivos e gerentes (procuram por opções para uma tomada de decisão).

Choo (2006, p.66), por sua vez, aponta "que a informação e o insight nascem no coração e na mente dos indivíduos, e que a busca e o uso da informação são um processo dinâmico e socialmente desordenado que se desdobra em camadas de contingências cognitivas, emocionais e situacionais.”. Ainda para Choo (2003, p.79), "as necessidades de informação variam de acordo com a profissão ou o grupo social do usuário, suas origens demográficas e os requisitos específicos da tarefa que ele está realizando".

Dervin e Nilan (1986, p.6), pontuam quais seriam esses os direcionamentos e suas conseqüentes tendências em relação aos estudos de necessidades e uso da informação com a mudança do paradigma tradicional para o alternativo: as necessidades dos usuários deveriam se tornar o foco central da operação de sistemas; os serviços de informação deveriam ser ajustados às necessidades específicas do indivíduo, e não o contrário; deveria ser mudado o foco dos sistemas de informação dirigidos a tecnologias e conteúdos para os dirigidos aos usuários e deveria ser colocado o foco nos próprios usuários.

Dentro desta perspectiva, destaca-se a busca e o uso dessas informações, focando nas necessidades informacionais dos usuários. O ciclo da necessidadebusca-uso, a partir das considerações citadas, baseia-se intrinsecamente em fatores profissional/social (ambiente), apreensão cognitiva (criação de significados) e 
Revista Tecnologia e Sociedade, Curitiba, v. 11, n. 23, 2015

ISSN (versão online): 1984-3526

ISSN (versão impressa): 1809-0044

reações emocionais (subjetividade). Os propósitos de sua prática estabelecem pontes de conhecimento e provocam sensações.

Le Coadic (1996, p.42) aponta que o conhecimento da necessidade de informação irá permitir a compreensão motivacional das pessoas que se envolvem em um processo de busca de informação, destacando a inter-relação entre as necessidades de informação, comportamento dos usuários e uso da informação.

A partir dessas considerações, é possível perceber que o consumo de uma informação passa por um critério de seletividade, e a maneira pela qual ela pode influenciar ou contribuir para a concepção de determinado trabalho serão fatores preponderantes na tomada de decisão.

Desse modo, o uso da informação, segundo Choo (2003, p.83), "engloba a totalidade da experiência humana: os pensamentos, sentimentos, ações e o ambiente onde eles se manifestam". Destacando ainda que não há como deixar de lado a lógica uso-necessidade-transmissão, as noções identitárias que constituem o usuário. Não se pode encará-lo como uma simples parte de um dinâmico sistema que se "desdobra em camadas de contingências cognitivas, emocionais e situacionais" (CHOO, 2003, p.66).

Do exposto, portanto, não há como analisar o usuário como mero espectador de uma proposta informativa, desconsiderando tudo que compõe suas noções de pertencimento, as ideologias e percepções desse sujeito.

Inúmeros são os modelos que se propõem a explicar os movimentos do usuário diante de uma necessidade informacional. Dentre esses inúmeros estudos, pode-se destacar o modelo de Taylor e a sua idéia de informação como valor agregado. $O$ processo de seleção, análise e julgamento transformam um dado em informação útil e contribui na questão pessoal e cultural, afetando as decisões das pessoas. Taylor aponta quatro níveis de necessidade: visceral (vaga sensação de insatisfação), consciente (a pessoa sabe a área de indecisão), formalizado (a pessoa já é capaz de formular uma pergunta ou tópico) e adaptado (a pergunta é traduzida para a linguagem do sistema). (CHOO, 2003)

O modelo de Kuhlthau (1999) traz as incertezas enraizadas no início, seleção, exploração e formulação de busca de informação. Esse itinerário surge com a necessidade que gera o consumo de diversas fontes. Ferreira (1997, p.175) reflete sobre o sense making de Brenda Dervin, afirmando que essa abordagem "procura 
Revista Tecnologia e Sociedade, Curitiba, v. 11, n. 23, 2015

ISSN (versão online): 1984-3526

ISSN (versão impressa): 1809-0044

entender os usuários com necessidades cognitivas, afetivas, psicológicas e fisiológicas".

Destaque também para o modelo de Ellis, que segue as seguintes definições: iniciar (início da busca); encadear (relação com outras informações importantes); navegar (área de interesse); diferenciar (filtragem e seleção de fontes); monitorar (acompanhamento da atualização); extrair (recuperar materiais de interesse); verificar (avaliação da validade da informação) e analisar (estabelecimento de ligações).

Para Le Coadic (1996, p.42), um estudo focado nas necessidades de informação deve responder questões como: "quem necessita da informação?, que tipo de informação?, para qual grupo de pessoas?, por que precisam delas?, quem decide quanto a essa necessidade?, quem seleciona?; que uso é dado ao que é fornecido?, que conseqüências resultam desse uso para o individuo, o grupo, a instituição, a sociedade em seu conjunto?"

De forma sucinta, Le Coadic (1996, p. 45) ainda apresenta as cinco etapas, as quais compõem o processo de análise das necessidades informacionais: identificar os usuários e os usos da informação; descrever a população-alvo e o ambiente; identificar as necessidades dessa população; avaliar as necessidades e descrever, comunicar e implementar as soluções.

\section{ETAPAS DE DESENVOLVIMENTO DE UM SISTEMA DE INFORMAÇÕES GERENCIAIS}

Segundo Laudon; Laudon (2004), sistemas de informação são compostos por um conjunto de componentes inter-relacionados que coleta (ou recupera), processa, armazena e distribui informações destinadas a apoiar a tomada de decisões, a coordenação e o controle de uma organização.

O desenvolvimento desse tipo de solução sistêmica obedece, ainda segundo os autores, às seguintes etapas:

- Análise de sistemas - é a fase de análise do problema a ser resolvido, na qual define-se o problema, identificam-se suas causas, especifica-se a solução, identificam-se os requisitos de informação a serem atendidos pela solução - 
Revista Tecnologia e Sociedade, Curitiba, v. 11, n. 23, 2015

ISSN (versão online): 1984-3526

ISSN (versão impressa): 1809-0044

quem precisa de qual informação, quando, onde e como -, e faz-se o estudo da viabilidade financeira, técnica e organizacional da solução.

- Projeto de sistemas - nessa fase define-se como o sistema cumprirá seus objetivos, a partir da elaboração do modelo contendo as especificações de forma e estrutura do sistema, abordando componentes organizacionais e tecnológicos da solução.

- Conclusão do processo - a terceira e última fase engloba as seguintes atividades:

- Programação - tradução das especificações de projeto para código de programa, em fase de programação do software.

- Teste - verificação de cada programa separadamente, do sistema de informação como um todo e dos sistemas com todas as partes envolvidas (usuários e administração).

- Conversão - é o processo de passagem do sistema antigo para o novo.

- Produção e manutenção - depois de instalado o novo sistema e concluída a conversão, é feita a verificação do cumprimento dos objetivos do sistema e levanta-se a necessidade de revisões. A manutenção diz respeito a mudanças em hardware, software, documentação ou procedimentos no sistema para as melhorias necessárias.

Este trabalho tem seu foco na primeira etapa de desenvolvimento da solução, acima descrita, denominada Análise de Sistemas, especificamente no que tange à identificação dos requisitos de informação (ou necessidades de informação) a serem atendidos pela solução, ou seja, no levantamento de quem precisa de qual informação, quando, onde e como.

\section{O CASO ESTUDADO: PERDAS NÃO-TÉCNICAS NA ENERGISA}

Segundo Camboim; Nóbrega (2010), o serviço de distribuição de energia elétrica envolve as chamadas perdas não técnicas, resultantes, entre outros, de ligações clandestinas e fraudes nos equipamentos medidores e têm sido foco de grande atenção por parte da Agência Nacional de Energia Elétrica - ANEEL e das empresas distribuidoras brasileiras. 
Revista Tecnologia e Sociedade, Curitiba, v. 11, n. 23, 2015

ISSN (versão online): 1984-3526

ISSN (versão impressa): 1809-0044

Essas perdas sempre foram motivo de preocupação para as empresas distribuidoras pelo vulto de recursos desviados que representa e, ainda mais pela obrigatoriedade imposta pela agência reguladora do setor (a ANEEL) de exercer um controle mais efetivo sobre as mesmas.

O grupo Energisa tem sede em Cataguazes, Minas Gerais. Esse grupo, à época do desenvolvimento da solução sistêmica, contava com cinco distribuidoras (hoje totalizando oito, após aquisição de outro grupo): uma em Minas Gerais, Uma no Rio de Janeiro, uma em Sergipe e duas na Paraíba (a Energisa Paraíba e a Energisa Borborema). Uma vez que o maior problema de perdas do grupo situavase na Paraíba, optou-se por localizar a solução sistêmica nesse estado.

De acordo com Camboim; Nóbrega (2010), o Grupo Energisa investiu ao longo de anos, um alto volume de recursos financeiros no combate a esse problema.

Entre as principais ações empreendidas destacadas pelas autoras estão: a adoção de soluções técnicas que tornam a rede de distribuição e os equipamentos medidores menos vulneráveis às práticas de furto e fraude de energia e as ações de fiscalização e regularização das instalações das unidades consumidoras. Para gerenciar essas ações e os recursos investidos, foi instituído no grupo um processo de negócio denominado Gestão de Perdas Não Técnicas, que cruza suas estruturas organizacionais, tendo etapas realizadas por diferentes departamentos. Esse processo tem como objetivo obter uma melhor relação de custos versus benefícios envolvendo um complexo processo decisório.

Conforme as autoras, com o intuito de dar apoio à tomada de decisão no processo de Gestão de Perdas Não Técnicas o Grupo Energisa optou por desenvolver, no ano de 2007, uma solução sistêmica que pudesse aumentar a eficácia deste processo. A escolha recaiu sobre a construção de um ambiente analítico corporativo, fundamentado na arquitetura de data warehouse, conforme se expõe no decorrer dessa investigação.

\section{PERCURSO METODOLÓGICO DA PESQUISA}

A partir do estudo de vários modelos de comportamento informacional presentes na literatura, elaborou-se, para o presente trabalho um roteiro de entrevista semi-estruturado com o intuito de identificar diversas etapas relacionadas 
Revista Tecnologia e Sociedade, Curitiba, v. 11, n. 23, 2015

ISSN (versão online): 1984-3526

ISSN (versão impressa): 1809-0044

à identificação de necessidades de usuários presentes no caso estudado. A intenção foi a de, a partir do leque e diversidade de informações coletadas, comparar com qual dos modelos de comportamento informacional o caso prático mais se assemelhava.

Esse roteiro de entrevista foi aplicado junto à profissional que ficou responsável por levantar informações sobre o comportamento informacional dos usuários internos da Energisa - uma engenheira de produção contratada para essa finalidade - de maneira a auxiliar na construção do data warehouse corporativo. A escolha pelo roteiro de entrevista semi-estruturada teve como justificativa o fato de se procurar manter uma linha pré-definida de investigação acerca dos pontos relativos aos modelos de interesse para o estudo a, ao mesmo tempo, dar espaço para que a entrevistada expusesse espontaneamente suas percepções para que se pudesse identificar novos problemas, interações, obtendo-se, assim, juízos de valor que fossem relevantes para a investigação. Como afirma Duarte (2005), a entrevista semi-estruturada inicia com um roteiro-base, porém, leva em consideração o processo de interlocução. "Trata-se de uma entrevista que conjuga a flexibilidade da questão não estruturada com um roteiro de controle, valorizando as respostas, o conhecimento e a disposição dos entrevistados" (DUARTE, 2005, p. 66).

Ainda conforme esse autor, essa forma de coleta contrai validade e confiabilidade quando se insere em determinados parâmetros: como a seleção de informantes capazes de responder as questões levantadas, que asseguram respostas aprofundadas e contextualizadas; recorte dos resultados que associe as informações obtidas com o conhecimento teórico previamente escolhido para a pesquisa.

A partir das respostas colhidas junto à engenheira de produção em questão, foi feita uma apreciação comparativa entre os pontos revelados no seu discurso e aqueles levantados no aporte teórico da investigação, acerca dos modelos de identificação de necessidades de usuários. Comparados os conteúdos, escolheu-se aquele modelo que mais se assemelhou à realidade estudada e construiu-se um quadro comparativo de forma a se evidenciar com mais clareza como essas etapas de identificação de necessidades de informação de fato ocorreu.

\section{DATA WAREHOUSE}


Revista Tecnologia e Sociedade, Curitiba, v. 11, n. 23, 2015

ISSN (versão online): 1984-3526

ISSN (versão impressa): 1809-0044

Conforme Laudon; Laudon (2004), um sistema de computador organiza dados segundo uma hierarquia que começa com bits e bytes e prossegue até campos, registros, arquivos e bancos de dados. Esses últimos se constituem em um grupo de arquivos relacionados, como, por exemplo, o arquivo de clientes de uma empresa, agrupado com arquivos contendo seus históricos pessoais e com arquivos financeiros sobre os mesmos pode criar um banco de dados sobre clientes.

O que se tem disponível imediatamente na maioria das empresas são somente dados correntes (dados históricos estariam disponíveis por meio de relatórios, o que tomaria muito tempo). Os dados geralmente estão fragmentados em sistemas operacionais separados, fazendo com que vários gerentes tomem decisões a partir de bases de conhecimento incompletas. Um grande problema desta modelagem de banco de dados é que se pode perder muito tempo localizando e coletando dados. O data warehouse ataca esse problema, integrando dados operacionais chave de toda a empresa de forma consistente, confiável e facilmente disponível para relatórios.

Laudon; Laudon (2004) e O'Brien (2004) argumentam que um data warehouse é um banco de dados que armazena dados correntes e históricos de potencial interesse dos gerentes da empresa. Estes dados têm origem em muitos sistemas operacionais centrais e de fontes externas cada qual com modelos de dados diferentes. Os dados, de aplicações diversas, são copiados para o data warehouse do banco de dados com a freqüência desejada (por hora, dia, semana, mês), são padronizados conforme um modelo de dados comum e consolidados de modo que possam ser usados por toda a empresa para análise gerencial e tomada de decisões. Os dados estão disponíveis a todos para acesso, mas não podem ser alterados.

\section{AS FASES DO PROJETO DO DATA WAREHOUSE NA ENERGISA}

Conforme análise dos dados coletados por Camboim; Nóbrega (2010), o projeto do desenvolvimento do Data Warehouse na Energisa (DWE) apresentou estreita correspondência com as fases de desenvolvimento de um sistema de informação em conformidade com a visão de Laudon; Laudon (2004), conforme esquematizado na Figura 1. 
Revista Tecnologia e Sociedade, Curitiba, v. 11, n. 23, 2015

ISSN (versão online): 1984-3526

ISSN (versão impressa): 1809-0044

São vários os sistemas transacionais presentes na empresa. A manipulação de dados de consumo de energia era feita via consultas aos seguintes: sistema de faturamento, o sistema comercial, sistema de ordem de serviço, sistema de georreferenciamento da rede e sistema de inspeção (onde se registram dados das inspeções).

Segundo dados coletados para essa pesquisa, já havia, por parte da alta direção, a idéia de centralizar a base de dados para gestão dessas perdas e de prover uma padronização para todo esse processo de gestão, por isso a necessidade de construção de uma solução sistêmica. Essa ausência de padronização na utilização dos dados oriundos desses diversos sistemas transacionais constituía-se num problema na hora de comparar o desempenho das diferentes distribuidoras, já que cada uma construía os indicadores requisitados pela diretoria de diferentes formas pelas diferentes unidades, com dados oriundos de fontes diversas e coletados em horários distintos (o que altera o valor da medição). Isso gerava uma falta de confiabilidade na informação, além do que a planilha eletrônica (que costumava ser a ferramenta utilizada para análise desses dados) não era um aplicativo seguro para geração de dados tão relevantes, que precisavam, inclusive, ser enviados à ANEEL.

Por isso, o grupo achou que esses procedimentos não vinham sendo feitos da forma mais adequada e optou pela solução do Data Warehouse (DW). Com isso, os dados que eles normalmente utilizavam seriam extraídos dessa base, colocados no DW, e a consulta seria apenas a partir do DW. Na forma de trabalho antiga, entendia-se que o melhor foco a ser dado em competências nos analistas de perdas era na expertise em informática, uma vez que tinham de consultar as bases de dados sobre consumidores dos diferentes sistemas transacionais da empresa. A idéia passou a ser retirar o foco da expertise em informática para foco num maior conhecimento das atividades do negócio.

Os gerentes idealizadores da solução na Energisa já tinham a idéia de que antes de ser iniciado o desenvolvimento do sistema em si deveriam mapear todo o processo a ser atendido pelo sistema - inserida na macro-fase conhecida como PréProjeto, segundo Camboim; Nóbrega (2010) e apresentada na Figura 1 - com o intuito de identificar as necessidades de informação de cada atividade do processo. Esse trabalho teve a participação de gerentes e funcionários envolvidos no 
Revista Tecnologia e Sociedade, Curitiba, v. 11, n. 23, 2015

ISSN (versão online): 1984-3526

ISSN (versão impressa): 1809-0044

processo, sob a coordenação de uma profissional de Engenheira de Produção contratada com a missão de conduzir tal mapeamento, e refletiu o modus operandi à época. Embora o projeto todo fosse relacionado às perdas, o suporte do DW não seria para o processo como um todo, mas apenas para algumas fases (por exemplo, inspeção em campo, embora fosse uma atividade mapeada, não teve relação com o uso do DW).

O processo começou a ser mapeado, entendendo-se que o mesmo era composto por diversas atividades. Cada uma dessas atividades foi minuciosamente descrita pela profissional responsável pelo levantamento, dentro de padrões técnicos previamente exigidos. O nível de detalhamento adotado no mapeamento foi tal que toda etapa que envolvesse tomada de decisão foi registrada.

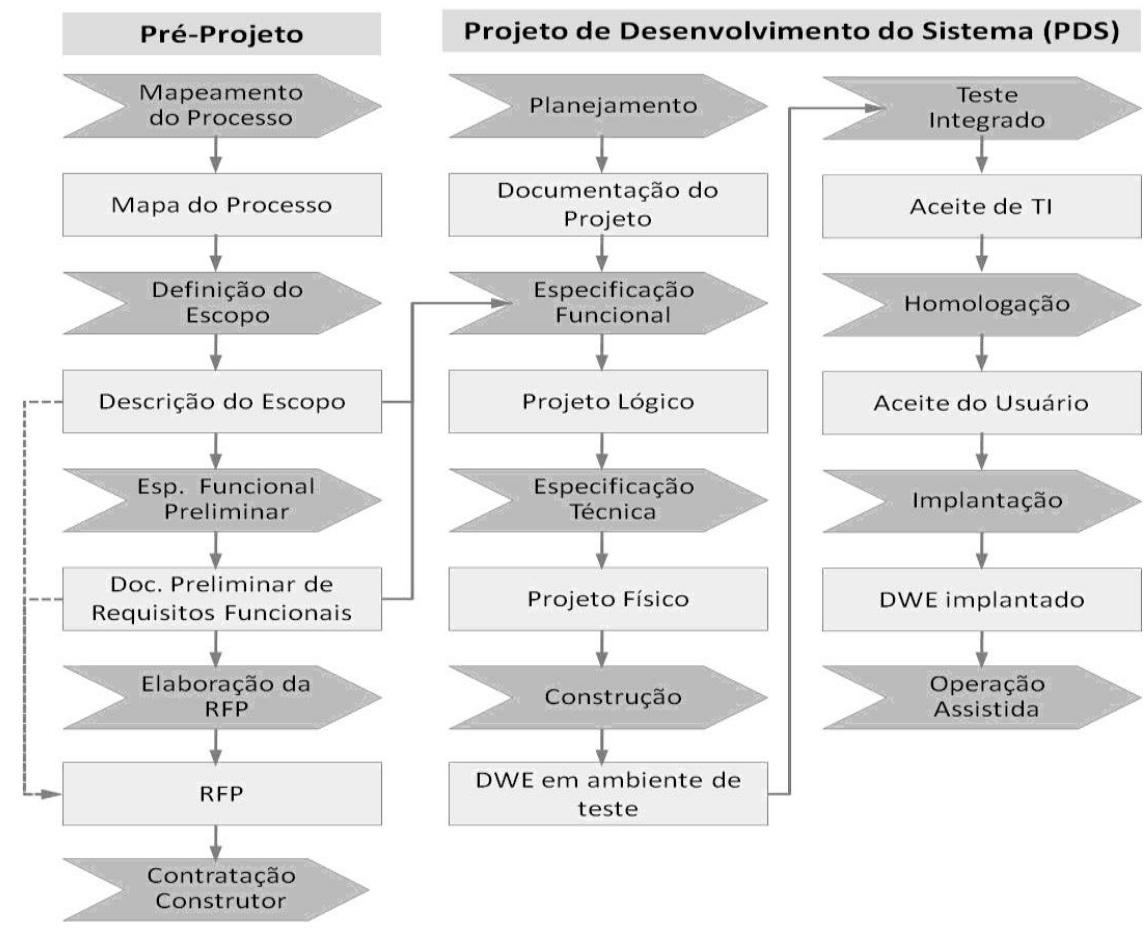

FIGURA 1: Fases e produtos do desenvolvimento do data warehouse do grupo Energisa. Fonte: Camboim; Nóbrega (2010).

Camboim; Nóbrega (2010) argumentam que a partir do produto da primeira fase, o Mapa do Processo, as áreas usuária e de BI (Business Inteligence) definiram conjuntamente o escopo do projeto. Essa definição baseou-se em três critérios: a) se o procedimento envolvia tomada de decisão; b) se os usuários enfrentavam dificuldades para tomada de decisão devido à falta de informação, baixa confiabilidade e/ou atraso no acesso às informações; c) se a solução para a necessidade específica do procedimento era viável técnica e economicamente. 
Revista Tecnologia e Sociedade, Curitiba, v. 11, n. 23, 2015

ISSN (versão online): 1984-3526

ISSN (versão impressa): 1809-0044

Como resultado dessa análise, dos dezenove procedimentos que compõem o processo de Gestão das Perdas Não Técnicas, cinco foram selecionados para serem atendidos pelo DWE. Esses cinco procedimentos, e seus respectivos desdobramentos, foram, então, descritos de forma textual para complementar a descrição gráfica e esclarecer detalhes do negócio, que não se evidenciavam no Mapa do Processo. Assim, o produto da fase de Definição do Escopo, denominado Descrição do Escopo, consistiu-se em um recorte do Mapa do Processo contendo apenas os cinco procedimentos selecionados, acrescidos das respectivas descrições textuais, tendo grande importância em todo o desenvolvimento do sistema, pois facilitou o diálogo entre os envolvidos no projeto, que se reportaram a uma referência única, com terminologia comum, baseada na perspectiva do usuário.

A segunda fase do Pré-Projeto, segundo as autoras, chamada Levantamento Preliminar de Requisitos, iniciou-se com a definição das pessoas envolvidas nesse processo. Foram selecionadas pessoas envolvidas, de todas as distribuidoras da Energisa, o que gerou um grupo de cerca de quinze pessoas, inicialmente. Foram feitas entrevistas com os principais usuários, conduzidas pelo gerente de $\mathrm{BI}$ (Business Intelligence) do grupo, também gerente do projeto, com a intermediação da profissional que coordenou o mapeamento do processo.

Com o Mapa do Processo definido, a engenheira de produção responsável estudou em cada atividade quais eram as necessidades de informação a serem supridas em cada uma delas, ressaltando que antes das entrevistas houve uma orientação referente à terminologia técnica e à solução de data warehouse. Nessas entrevistas, os usuários internos apresentaram suas planilhas, seus modelos de consultas e outros documentos. Cada entrevista foi guiada por um roteiro básico de perguntas e focada em uma etapa específica do processo.

Num segundo momento, foram feitas entrevistas individuais com esses usuários internos para um maior detalhamento sobre o que significavam as planilhas, gráficos e análises apresentadas por eles. Para cada atividade do processo mapeada foram feitas perguntas como: como você realiza essa atividade? Quais as informações que você utiliza? Como você combina essas informações?. A intenção foi a de tentar traduzir as necessidades dos usuários. Esse processo fluía muito facilmente com alguns dos usuários, outros, porém, apresentaram mais 
Revista Tecnologia e Sociedade, Curitiba, v. 11, n. 23, 2015

ISSN (versão online): 1984-3526

ISSN (versão impressa): 1809-0044

dificuldade em articular essas necessidades, o que constituiu-se num problema relativamente grande.

Por isso, como suporte às entrevistas, foi feita também a análise documental das planilhas que eram utilizadas por eles (onde foram analisados campo por campo, coluna por coluna, o que é que significava cada item, de onde o usuário tinha retirado aquela informação etc.), bem como de todos os documentos que eles utilizavam nas tarefas. Quase todos faziam consultas direto na base de dados, cruzavam dados de um sistema com o de outro e combinavam as informações da forma que se achasse mais adequada numa planilha eletrônica, além de mais uma gama de procedimentos desenvolvidos pelos próprios da forma que melhor thes conviesse. O resultante desses cruzamentos seriam produtos como, por exemplo, listas de consumidores para inspeção, um dos pontos importantes no trabalho de combate a essas perdas. O grau de envolvimento dos usuários no projeto foi aumentando cada vez mais, à medida que entendiam melhor do que se tratava.

Segundo levantamento da pesquisa, a partir desse levantamento os envolvidos no projeto procuraram estudar a melhor forma de execução de cada atividade, dados necessários para tal execução, informações que seriam geradas por cada atividade etc.

Nesse ponto foi detectado que a necessidade que os usuários estavam expondo nas entrevistas nem sempre correspondia à necessidade técnica para a realização da tarefa. Essa avaliação foi feita e discutida entre os próprios usuários nessas reuniões. A reunião de várias pessoas que realizavam a mesma atividade em empresas diferentes fez com que se começasse uma troca de experiências que resultou em questionamentos sobre a forma como cada unidade executava suas atividades. A partir daí, surgiu um trabalho comparativo - entre o que os usuários apontavam como necessidade e o que seria mais adequado tecnicamente para a correta execução da atividade - o que gerou uma análise crítica. Essa análise crítica, que teve início no grupo, acabou por ser levada às instâncias da alta gerência e foi a base para a especificação dos requisitos de informação (traduzida em forma de documento final da especificação dos requisitos). Coube à engenheira de produção traduzir o que os usuários queriam para uma linguagem inteligível para a informática (e não necessariamente para a linguagem da informática). Seu trabalho foi, pois, 
Revista Tecnologia e Sociedade, Curitiba, v. 11, n. 23, 2015

ISSN (versão online): 1984-3526

ISSN (versão impressa): 1809-0044

prover os programadores dos dados que necessitavam sobre o trabalho dos usuários.

Finalmente, feito o mapa do processo, as entrevistas em grupo e individuais o que gerou os chamados, requisitos funcionais -, construiu-se um documento com esses requisitos que foi utilizado pra fazer a contratação da empresa que iria construir a solução. A partir desse documento, as várias empresas que concorreram apresentaram suas propostas de solução.

De cordo com Camboim \& Nóbrega (2010), durante o mapeamento foram identificadas oportunidades de melhoria em algumas etapas do processo, para as quais foram traçados planos de ação. Algumas dessas melhorias dependiam de ajustes nos Sistemas de Processamento de Transações, para os quais foram abertas solicitações de melhoria. Com isso, garantiu-se que o data warehouse fosse construído para atender ao processo já otimizado, com base em fontes de dados adequadas às necessidades correntes da área usuária.

Para as empresas proponentes, a disponibilização desse documento de requisitos funcionais facilitou a elaboração de suas propostas, pois apresentavam as necessidades básicas dos usuários com clareza e nível de detalhamento incomuns nesse ramo de atividade. Isso foi considerado um atenuante dos riscos do projeto e ainda permitiu que as empresas previssem um prazo mais curto que o usual para a fase de Especificação Funcional, reduzindo o custo do projeto.

Com isso, abriu-se um edital, algo parecido com uma licitação, em que as empresas apresentaram propostas. Foram feitas avaliações das propostas da parte técnica e foram atribuídas notas. Depois novas avaliações a respeito de outros requisitos para as empresas, donde saiu a empresa vencedora da concorrência, uma empresa de Campinas, com larga experiência no assunto. Assim, à empresa contratada coube apenas a construção da solução, não precisando fazer o trabalho de rastreamento de necessidades, que foi feito pelo próprio pessoal da empresa, profundamente conhecedor do negócio. Fisicamente o DWE situa-se na Energisa Paraíba, mas todas as unidades da Energisa espalhadas pelo país podem acessálo.

O software resultante foi orientado para tarefas específicas e foi construído atividade por atividade. Inicialmente, isso gerou nos usuários receio de perderem o acesso caso surgissem, no futuro, necessidades distintas das que eles tinham 
Revista Tecnologia e Sociedade, Curitiba, v. 11, n. 23, 2015

ISSN (versão online): 1984-3526

ISSN (versão impressa): 1809-0044

relatado na fase de coleta de dados para a construção do DWE, já que nessa atividade é comum surgirem novas necessidades. Isso reforçou no grupo a necessidade de se descrever a atividade da forma mais detalhada possível e absorveu um tempo considerável de trabalho junto aos usuários (cerca de 5 meses). Inicialmente, houve relutância dos usuários em confiar nos dados gerados pelo DWE, uma vez que anteriormente eram construídos por eles próprios.

Inicialmente o DWE começou funcionando em paralelo com o sistema antigo, em fase de teste. Um ponto importante para assegurar a correta leitura das necessidades desses usuários foi a comparação entre os dados gerados pelo DWE e aqueles gerados na forma anterior. Esse período de confrontação de dados foi relativamente longo, porque houve investigação minuciosa junto ao pessoal de informática a cada diferença apresentada, resultando nos necessários ajustes.

\section{ANÁLISE DO CASO À LUZ DO MODELO DE NECESSIDADES DE INFORMAÇÃO DE LE COADIC}

A partir da análise dos dados coletados para esse estudo, apresentados no item anterior, através da entrevista semi-estruturada junto à engenheira de produção responsável pelo mapeamento do processo de gestão de perdas não-técnicas na Energisa, pode-se extrair algumas conclusões.

No que diz respeito ao tipo de usuários a ser atendido, conforme classificação de Figueiredo (1999, p.19), trata-se de um grupo de executivos e gerentes e que, portanto, buscam por opções para uma tomada de decisão.

Também segundo visão de Le Coadic (1996), que classifica as necessidades de informação em função do conhecimento (necessidade de saber) ou em função da ação (para realização de atividades humanas, profissionais e pessoais), pode-se afirmar que, nesse estudo, as necessidades apresentadas repousam no segundo grupo: em função da ação.

Observando-se as etapas do rastreamento de necessidades de informação empreendidas nesse estudo, conforme item anterior, observa-se que o caso aproxima-se bastante das cinco etapas de análise das necessidades de informação propostas por Le Coadic (1996), conforme revisão teórica anterior, e pode ser apresentada em forma comparativa no quadro 1 abaixo. 
Revista Tecnologia e Sociedade, Curitiba, v. 11, n. 23, 2015

ISSN (versão online): 1984-3526

ISSN (versão impressa): 1809-0044

\begin{tabular}{|c|c|}
\hline $\begin{array}{l}\text { Etapas para análise de necessidades de } \\
\text { informação (Le Coadic, 1996) }\end{array}$ & Etapas percorridas no projeto \\
\hline $\begin{array}{l}\text { 1. Identificar os usuários e o uso da } \\
\text { informação }\end{array}$ & $\begin{array}{l}\text { Usuários: Foram identificadas as pessoas } \\
\text { diretamente envolvidas na gestão de perdas } \\
\text { não-técnicas nas cinco diferentes unidades } \\
\text { da empresa. } \\
\text { Usos: conhecidos a partir da construção do } \\
\text { Mapa do Processo. }\end{array}$ \\
\hline 2. Descrever a população-alvo e o ambiente & $\begin{array}{l}\text { A população-alvo foi restrita àquelas pessoas } \\
\text { que atuavam nas cinco etapas do processo } \\
\text { de gestão de perdas não-técnicas eleitas para } \\
\text { serem atendidas pela solução, informação } \\
\text { levantada na Descrição do Escopo. O } \\
\text { ambiente envolveria os setores relacionados } \\
\text { à gestão de perdas não-técnicas nas cinco } \\
\text { unidades da empresa. }\end{array}$ \\
\hline $\begin{array}{l}\text { 3. Identificar as necessidades dessa } \\
\text { população }\end{array}$ & $\begin{array}{l}\text { Feito através de entrevistas em grupo, } \\
\text { entrevistas individuais e análise documental. }\end{array}$ \\
\hline 4. Avaliar as necessidades & $\begin{array}{l}\text { Foram feitas durante as próprias reuniões do } \\
\text { grupo para entrevistas, além de } \\
\text { individualmente pela Engenheira de Produção } \\
\text { responsável pelo mapeamento. Nesse } \\
\text { sentido, comparou-se o que o cada usuário } \\
\text { relatava como necessidade e o que os } \\
\text { requisitos técnicos apontavam como sendo } \\
\text { necessidade para a melhor execução de cada } \\
\text { tarefa. }\end{array}$ \\
\hline $\begin{array}{l}\text { 5. Descrever, comunicar e implantar as } \\
\text { soluções }\end{array}$ & $\begin{array}{l}\text { A descrição dessas necessidades foi feita via } \\
\text { especificações funcionais e sua comunicação } \\
\text { foi feita via Documento Preliminar de } \\
\text { Requisitos Funcionais, mostrado na Figura } 1 . \\
\text { Após propostas das empresas interessadas } \\
\text { em construir a solução, procedeu-se à } \\
\text { escolha de uma delas e consequente } \\
\text { implantação da solução. }\end{array}$ \\
\hline
\end{tabular}

Quadro 1: Quadro comparativo entre as etapas do projeto e as etapas do modelo de Le Coadic. Fonte: Elaboração Própria (2014).

Embora outros modelos sejam entendidos como mais apropriados ao levantamento de necessidades em ambientes organizacionais, o modelo de Le Coadic (1996) mostrou bastante aderência ao caso, o que leva a inferir que as condições individuais de cada caso é que devem tornar um ou outro modelo mais 
Revista Tecnologia e Sociedade, Curitiba, v. 11, n. 23, 2015

ISSN (versão online): 1984-3526

ISSN (versão impressa): 1809-0044

apropriado para análise, independentemente do ambiente. Além do que, uma crescente tendência em retirar o foco desses estudos dos sistemas e leva-los aos usuários deve levar também a uma compatibilização de vários modelos de identificação de necessidades a vários diferentes tipos de ambientes.

\section{CONSIDERAÇÕES FINAIS}

O presente trabalho teve por finalidade fazer uma reflexão acerca da identificação de necessidades de informação de usuários internos numa empresa nacional de distribuição de energia elétrica, especificamente no que diz respeito à execução do trabalho relacionado a uma atividade tida como crítica para o negócio, a Gestão de Perdas Não-Técnicas. A identificação dessas necessidades visava a prover de subsídios a construção de uma solução sistêmica baseada na arquitetura de um data warehouse, de maneira que esses usuários pudessem realizar suas funções de forma mais otimizada a partir da consulta a essa base de dados unificada.

A fase de mapeamento do processo - relativo à Gestão de Perdas Não Técnicas - mostrou-se fundamental para o êxito da fase de identificação das necessidades dos usuários envolvidos nesse processo. Através dela, o grupo envolvido no trabalho pode ter o acesso mais próximo possível ao universo do usuário, entendendo-o e sendo capaz de idealizar o percurso cognitivo do mesmo em busca de informações para transferí-lo aos desenvolvedores do software. Buscou-se entender as necessidades de informação estudando o processo de busca do usuário para cada atividade e confrontando-o com as necessidades técnicas exigidas para o andamento do processo. Tal mapeamento corrobora com a idéia de que a pergunta a ser respondida deva ser "informação para quê?", ao invés de "informação para quem?".

A participação dos usuários no esclarecimento de suas necessidades foi fundamental pois, embora a decisão de se construir esse DW para o combate às perdas não-técnicas tenha partido da alta cúpula do grupo, os usuários foram chamados a compartilharem sua forma de trabalho - suas necessidades informacionais, seu processo de busca - de modo que, naturalmente, nas entrevistas em grupo e individuais, essas necessidades fossem sendo melhor 
Revista Tecnologia e Sociedade, Curitiba, v. 11, n. 23, 2015

ISSN (versão online): 1984-3526

ISSN (versão impressa): 1809-0044

esclarecidas até mesmo para os próprios. Aqui, os responsáveis pelo projeto pontuaram dificuldades por parte de alguns usuários em articularem suas necessidades.

É interessante ressaltar que para alguns dos usuários internos, o processo de busca de informação se dava de maneira mecânica, porém, o negócio sempre apresentava necessidades novas. Esse tipo de perda apresenta um dinamismo muito grande por parte dos fraudadores, que se mostram criativos e forçam também a criatividade da empresa na busca de soluções para combatê-las, para que se tome as medidas para inspeção, entendendo que, por isso, listas de inspeção para detecção de fraudes não obedecem a um padrão. Cada empresa tem suas próprias especificidades e pode traçar suas próprias estratégias para combater esse tipo de problema, por exemplo: combater apenas consumidores maiores.

Não houve uma imposição na maneira tida como a correta de se executar o trabalho, houve um processo de elaboração dessas necessidades em conjunto com a participação dos usuários internos, sempre articulada por profissionais de grande conhecimento técnico do negócio que funcionaram como maestros. Isso fez com que o grupo de usuários realmente se sentisse parte da construção dessa nova forma de gerenciar as perdas.

Frise-se também, que esse trabalho em grupo de identificação de necessidades de informação, fez com que todos eles questionassem seus próprios procedimentos de trabalho, não só reelaborando, nos usuários, suas próprias necessidades de informação, como também melhorando alguns sistemas transacionais da empresa.

Hoje o sistema está 100\% implantado. Após a implantação e uso dessa solução sistêmica, a empresa pôde perceber que o nível de perdas da Energisa Paraíba, que era o mais elevado do grupo, apresentou uma redução bastante significativa, já tendo diminuído, no tempo presente, até o nível regulatório exigido. Segundo dados coletados na entrevista, a empresa credita o sucesso no uso da solução sistêmica à clareza e nível de detalhamento das necessidades básicas dos usuários apresentadas nos requisitos do projeto, incomuns nesse ramo de atividade, segundo parecer da empresa contratada para desenvolver a solução. Além da centralização dos dados em um único banco de dados, o trabalho de rastreamento de necessidades reduziu redundâncias de dados, armazenamento de dados errados 
Revista Tecnologia e Sociedade, Curitiba, v. 11, n. 23, 2015

ISSN (versão online): 1984-3526

ISSN (versão impressa): 1809-0044

e contribuiu tão proficuamente para a construção do programa que fomentou uma interface fácil de operar, o que aumentou a rapidez e precisão do trabalho executado.

\section{REFERÊNCIAS BIBLIOGRÁFICAS}

BAPTISTA, Sofia Galvão. Estudos de usuários: visão global dos métodos de coleta de dados. In: Perspectivas em Ciência da Informação, v.12, n.2, p. 168-184, mai./ago. 2007. Disponível em: < http://www.scielo.br/pdf/pci/v12n2/v12n2a11.pdf>. Acesso em: 01 jul 2014.

CAMBOIM, Luzia G.; NÓBREGA, Mariana M.. Aspectos do desenvolvimento de um datawarehouse corporativo em uma distribuidora de energia elétrica: um estudo de caso. In:.XVII SIMPÓSIO DE ENGENHARIA DE PRODUÇÃO Anais... 2010, Bauru-SP.

CAPURRO, Rafael. Epistemologia e ciência da informação. In: ENCONTRO NACIONAL DE PESQUISA EM CIÊNCIA DA INFORMAÇÃO, 5., 2003, Belo Horizonte. Anais... Belo Horizonte: Associação Nacional de Pesquisa e Pós-Graduação em Ciência da Informação, 2003.

$\mathrm{CHOO}$, Chun Wei. A organização do conhecimento: Como as organizações usam a informação para criar significado, construir conhecimento e tomar decisões. Editora Senac: São Paulo, 2003.

$\mathrm{CHOO}$, Chun Wei. Como ficamos sabendo - um modelo de uso da informação. In: A organização do conhecimento: como as organizações usam a informação para criar significado, construir conhecimento e tomar decisões. 2. Ed. São Paulo: Ed. SENAC, 2006, Cap. 2, p. 63-120.

DERVIN, Brenda; NILAN, Michael. Information Needs and Uses. Annual Review of Information Science and Technology, v.21, 1896.

DUARTE, Jorge. Entrevista em profundidade. In: DUARTE, Jorge; BARROS, Antonio (orgs.). Métodos e técnicas de pesquisa em comunicação. São Paulo: Atlas, 2005.

FERREIRA, Sueli Mara Soares Pinto. Novos paradigmas e novos usuários da informação. In: Ciência da Informação, v.25, n.2. Disponível em: < http://scholar.google.com.br/citations?view_op=view_citation\&hl=pt-

BR\&user=Q9JDGqgAAAAJ\&citation_for_view=Q9JDGqgAAAAJ:d1gkVwhDpl0C>. Acesso em: 02 jul 2014.

FIGUEIREDO, Helton de Araújo; MORAIS, Laudereida Eliana Marques; RAMALHO, Francisca Arruda. Busca da informação para qualificação: um estudo com candidatos ao mestrado em Ciência da Informação do Programa de Pós-graduação em Ciência da Informação - UFPB.In: Informação e Sociedade: estudos, João Pessoa, v. 23, n. 12, p. 99-111. mai/ago 2013. Disponível em: <http://www.informacaoesociedade.ufpb.br>. Acesso em: 4 abr. 2014.

FIGUEIREDO, Nice. Paradigmas modernos da Ciência da Informação. São Paulo: Polis/ABP, 1999.

GONZÁLEZ DE GOMEZ, Maria Nélida. O objeto de estudo da Ciência da Informação: paradoxos e desafios. In: Ci. In., Brasília. 117-122, jul./dez. 1990. Disponível em: < 
Revista Tecnologia e Sociedade, Curitiba, v. 11, n. 23, 2015

ISSN (versão online): 1984-3526

ISSN (versão impressa): 1809-0044

http://revista.ibict.br/ciinf/index.php/ciinf/article/viewFile/1376/1001>. Acesso em: 29 jun 2014.

GUINCHAT, Claire; MENOU, Michel. Introdução geral às ciências e técnicas da informação e documentação. Brasília: IBICT, 1994.

KUHLTHAU,C. The role of experience in the information search process of an early carrer information worker: perceptions of uncertainty, complexity, construction, and sources. Journal of the American Society for information Science, v. 50, n.5,p. 399-412, 1999.

LAUDON, Keneth C.; LAUDON, Jane P. Sistemas de informações gerenciais: administrando a empresa digital. São Paulo: Pearson Prentice Hall, 2004.

LE COADIC, Yves-François. A ciência da informação. (Tradução: Maria Yêda F. S. de Filgueiras). Brinquet de Lemos: Brasília, 1996.

MIRANDA, Silvânia. Como as necessidades de informação podem se relacionar com as competências informacionais. Ci. Inf., Brasília, v. 35, n. 3, p. 99-114, set./dez. 2006. Disponível em: < http://www.scielo.br/pdf/ci/v35n3/v35n3a10.pdf>. Acesso em: 28 jun 2014.

O'BRIEN, James A. Sistemas de informações e as decisões gerenciais na era da internet. São Paulo: Saraiva, 2004.

SANZ CASADO, Elías. Manual de estudios de usuarios. Madrid: Pirámide, 1994.

\section{APÊNDICE 1}

\section{ROTEIRO DA ENTREVISTA}

1-) O que levou a Energisa a buscar a construção de um data warehouse? Qual o objetivo?

2-) Como esse banco de dados trabalhava para atingir esse objetivo? Qual era a função dele exatamente?

3-) Quais as etapas seguidas pela coleta de dados para identificar as necessidades dos usuários internos de forma a construir o data warehouse? Como foram estruturadas essas etapas?

4-) Quais os instrumentos de coleta de dados utilizados junto a esses usuários? De que forma foram utilizados?

5-) Quanto tempo levou para a conclusão das atividades?

6-) Quantas pessoas participaram do levantamento de dados?

7-) As necessidades expostas pelos usuários coincidiam com o que se esperava antes da coleta? Em caso negativo, onde estavam as diferenças?

8-) Quais as dificuldades encontrados no restreamento das necessidades desses usuários?

9-) Como foi a cooperação dos usuários nesse processo de levantamento de necessidades? 
Revista Tecnologia e Sociedade, Curitiba, v. 11, n. 23, 2015

ISSN (versão online): 1984-3526

ISSN (versão impressa): 1809-0044

10-) A partir do levantamento das necessidades dos usuários internos, como se deu a construção da solução propriamente dita?

11-) Como foi a implantação do sistema? Quais os problemas identificados nessa fase?

12-) Houve treinamento para os usuários sobre o uso desse sistema?

13-) Como a empresa avalia os resultados alcançados pelo uso do DW? 